\title{
COMPORTAMENTO VEGETATIVO E PRODUTIVO DE VIDEIRAS 'CABERNET SAUVIGNON' CULTIVADAS SOB COBERTURA PLÁSTICA ${ }^{1}$
}

\author{
CLENILSO SEHNEN MOTA², CASSANDRO VIDAL TALAMINI DO AMARANTE ${ }^{3}$, \\ HENRIQUE PESSOA DOS SANTOS ${ }^{4}$, ODIMAR ZANUZO ZANARDI ${ }^{5}$
}

RESUMO: O uso de cobertura plástica no cultivo de videira encontra-se em expansão no Rio Grande do Sul, por ser uma alternativa que visa a proteger as plantas da precipitação pluvial e do granizo. O objetivo deste estudo foi avaliar os impactos de uma cobertura plástica translúcida e impermeável sobre a fenologia, o crescimento (de ramos, folhas, cachos e bagas) e a produtividade em videiras 'Cabernet Sauvignon' (Vitis vinifera L.), com cinco anos de idade, conduzidas em sistema 'Y', sobre porta-enxerto Paulsen 1103. O experimento, conduzido no município de Caxias do Sul-RS, seguiu o delineamento em blocos ao acaso, tendo os tratamentos sem e com cobertura plástica, com quatro repetições de 15 plantas (unidade experimental). As alterações microclimáticas impostas pela cobertura plástica não foram expressivas para alterar a fenologia da videira. As plantas cultivadas sob cobertura plástica apresentaram maiores valores de comprimento e massa fresca de ramos e de área, e massa seca foliar em comparação às plantas descobertas. O peso e o diâmetro de bagas foram superiores nas videiras cobertas apenas no início do ciclo e não diferiram próximo da colheita. As demais variáveis analisadas não foram afetadas pela cobertura plástica. A cobertura plástica interferiu no crescimento vegetativo das plantas, mas não afetou a produção.

Termos para indexação: Vitis vinifera L., cultivo protegido, fenologia, crescimento, produção de frutos.

\section{VEGETATIVE GROWTH AND YIELD OF 'CABERNET SAUVIGNON' GRAPEVINE UNDER OVERHEAD PLASTIC COVERING}

\begin{abstract}
There is an increasing adoption of overhead plastic covering for grapevines in the State of Rio Grande do Sul, Southern Brazil, to protect the plants from rain and hail storms. This study was carried out to evaluate the impacts of overhead plastic covering with a translucent and water-proof plastic film on phenological, growth (of branch, leaves, clusters, and berries), and yield attributes of five years old 'Cabernet Sauvignon' grapevines (Vitis vinifera L.) on Paulsen 1103 rootstock raised as 'Y' management system. The experiment was carried out in Caxias do Sul, State of Rio Grande do Sul, and followed a randomized block design, with two treatments (uncovered and covered plants) and four replicates of 15 plants (experimental unit). The micro-environmental changes imposed by the cover did not affect grapevines phenology. The grapevines under the cover had higher values for branches growth (length and fresh mass), and leaf expansion (area and dry mass) than the uncovered ones. The berries weight and diameter were superior on grapevines under covering plastic only at earlier stages of fruit growth but not at harvest. The other variables assessed were not affected by the cover. The results show that overhead plastic covering can interfere with vegetative growth without affecting yield.
\end{abstract}

Index terms: Vitis vinifera L., protected cultivation, phenology, growth, fruit yield.

\section{INTRODUÇÃO}

A Serra Gaúcha é a principal região produtora de uvas e vinhos do Brasil. Todavia, possui condições climáticas desfavoráveis, devido ao elevado índice pluviométrico e à alta umidade relativa do ar, principalmente na época de colheita. Sendo assim, a vitivinicultura na região somente se torna possível com um rigoroso sistema de controle preventivo e curativo de doenças fúngicas da parte aérea, elevando os custos de produção. Em muitos anos, as safras são antecipadas, ocorrendo, assim, colheita fora do ponto ideal de maturação da uva. Essa antecipação, que tem como intuito evitar perdas por podridões favorecidas pelas chuvas de verão, compromete a qualidade final da uva, tanto para consumo in natura como para processamento (Tonietto, 2003). Em alguns anos, pode haver ainda a ocorrência de granizo, que causa ferimentos nas plantas e favorece a infecção por patógenos.

O uso de cobertura plástica no cultivo de videiras tornase, assim, uma alternativa que visa a proteger as plantas da precipitação pluvial e do granizo. Essa técnica encontra-se em expansão no Nordeste do Brasil, no Rio Grande do Sul e em Santa Catarina, com áreas atualmente cobertas de aproximadamente $700 \mathrm{ha}, 80 \mathrm{ha}$ e $70 \mathrm{ha}$, respectivamente, sendo usada principalmente em uva fina de mesa (Mota, 2007). Farias et al. (1993) observaram que a cobertura com filme plástico liso, devido às suas características ópticas, atua como dispersante da radiação solar, aumentando a fração difusa de luz no interior do ambiente protegido. Papadakis et al. (2000) citam que a radiação difusa pode ter um efeito desejável nos processos fotossintéticos, pois é multidirecional e penetra melhor através do dossel da

(Trabalho 079-07). Recebido em: 26-03-2007.Aceito para publicação em: 23-08-2007

${ }^{2}$ Acadêmico do Curso de Mestrado em Produção Vegetal, Bolsista da CAPES. Centro de Ciências Agroveterinárias (CAV), Universidade do Estado de Santa Catarina (UDESC), Av. Luiz de Camões, 2090, Caixa Postal 281, CEP 88520-000, Lages-SC. E-mail: clenilso@yahoo.com.br ${ }^{3}$ Ph.D., Bolsista de Produtividade em Pesquisa do CNPq, Professor do Curso de Agronomia, CAV/UDESC, Lages-SC. E-mail: amarante@cav.udesc.br. ${ }^{4}$ Dr., Pesquisador da Embrapa Uva e Vinho. Rua Livramento, 515, Caixa Postal 130, CEP 95700-000, Bento Gonçalves-RS. E-mail: henrique@cnpuv.embrapa.br

${ }^{5}$ Acadêmico do Curso de Agronomia, Bolsista de Iniciação Científica do CNPq. CAV/UDESC, Lages-SC. E-mail: odimarzanardi@yahoo.com.br 
cultura, podendo, assim, compensar em parte a opacidade dos filmes plásticos.

O sombreamento ocasionado pela cobertura plástica pode tanto estimular o crescimento vegetativo de ramos e folhas como, também, retardar o ciclo fenológico das plantas (Lambers et al., 1998). Em contrapartida, ao evitar a precipitação pluviométrica na linha de cultivo, a cobertura pode provocar estresse hídrico às plantas e, assim, reduzir o crescimento vegetativo (Gu et al., 2004; Souza et al., 2005) e antecipar a maturação (Smart \& Coombe, 1983) e o ciclo fenológico. No caso da videira, um estresse hídrico moderado pode ainda adicionar qualidade enológica à uva, pois aumenta os níveis de açúcares nas bagas (Jackson \& Lombard, 1993).

Este trabalho foi conduzido visando a avaliar o comportamento vegetativo e produtivo da videira 'Cabernet Sauvignon’ sob cobertura plástica, na região da Serra Gaúcha.

\section{MATERIAL E MÉTODOS}

O experimento foi conduzido no ciclo de 2005/2006, em uma propriedade particular na comunidade de Quarta Légua, no município de Caxias do Sul-RS, situada a $684 \mathrm{~m}$ de altitude, latitude $29^{\circ} 13^{\prime} 34^{\prime \prime} \mathrm{S}$ e longitude $51^{\circ} 06^{\prime} 45^{\prime \prime} \mathrm{W}$, com valores médios anuais de temperatura, umidade relativa e precipitação de $16,9^{\circ} \mathrm{C}, 72,4 \%$ e $1.712 \mathrm{~mm}$, respectivamente. O solo no local do experimento é um Cambissolo Húmico álico de textura argilosa.

Foram utilizadas videiras (Vitis vinifera L.) 'Cabernet Sauvignon' com cinco anos de idade sobre porta-enxerto Paulsen 1103, conduzidas em sistema "Y", com espaçamento entre plantas de $1,2 \mathrm{~m}$ e entre linhas de $3,0 \mathrm{~m}$, obtendo-se, com isso, uma densidade de 2.778 plantas por hectare. O trabalho seguiu o delineamento em blocos ao acaso, com quatro repetições e 15 plantas úteis por repetição. Os tratamentos utilizados foram sem e com cobertura plástica. $\mathrm{O}$ material utilizado na cobertura foi lona plástica trançada de polipropileno transparente, impermeabilizada com polietileno de baixa densidade, aditivada com filtro antiultravioleta, com $150 \mu \mathrm{m}$ de espessura e $2,65 \mathrm{~m}$ de largura.

No tratamento com cobertura, a lona plástica apresentava duas safras de uso, sem ser retirada em momento algum (as plantas foram cobertas em outubro de 2004). A cobertura plástica foi posicionada ao longo da linha de plantio, seguindo a orientação norte-sul, permanecendo aberturas no espaço entre linhas de $0,85 \mathrm{~m}$. Os plásticos foram dispostos sobre fios metálicos e esses sobre arcos de aço galvanizado, que, por sua vez, foram fixados sobre a estrutura de concreto, que dá sustentação e forma ao sistema de condução.

A poda foi executada no dia 31-08-2005, não se fazendo uso de cianamida hidrogenada para promover brotação. Desde o início da brotação, avaliou-se a fenologia, segundo a escala descrita por Lorenz et al. (1995), sendo monitorada uma planta marcada por repetição, em intervalos de aproximadamente 14 dias, durante todo o ciclo vegetativo/produtivo. A fenologia foi expressa em percentual de ramos por ponto da escala em cada data de avaliação. Nas mesmas plantas, avaliou-se o número total de folhas, sendo essas classificadas em folhas de ramo (broto originário de uma gema formada no ciclo anterior) e em folhas de feminela (broto originário de uma gema secundária que vegeta no mesmo ano em que é formada). Além disso, determinaram-se o número de ramos e o número de cachos, em duas plantas por repetição. O número de folhas, cacho e ramos foi avaliado no dia 19-01-2006. A contagem do número de bagas por cacho foi realizada na data da colheita (24-03-2006).

$\mathrm{O}$ crescimento dos ramos foi avaliado quanto à massa e o comprimento de entrenó, em cinco datas (22-11-2005, 05 e 30-012006, 09-03-2006 e 06-04-2006), durante o período vegetativo/ produtivo. Para isso, foram coletadas quatro amostras de ramos por repetição, sendo que cada amostra foi retirada da porção mediana dos ramos e continha quatro gemas (três entrenós). A massa do ramo foi obtida em uma balança analítica, e o comprimento de entrenó foi medido com auxílio de uma régua graduada.

Os atributos foliares foram quantificados através de avaliações de área, área específica e massa seca, utilizando-se de amostras de cinco folhas em cada repetição e data de amostragem. A área foliar foi obtida com o auxílio de um medidor de área foliar Li-Cor, modelo LI-3100. A massa seca foliar foi quantificada em balança analítica, após secagem em estufa a $65^{\circ} \mathrm{C}$, com circulação forçada de ar, por 72 horas. A área foliar específica $\left(\mathrm{cm}^{2} \mathrm{~g}^{-1}\right)$ foi calculada pela divisão da área $\left(\mathrm{cm}^{2}\right)$ pela massa seca $(\mathrm{g})$ foliar. Os atributos foliares relativos aos ramos foram quantificados em quatro datas (22-11-2005, 05-01-2006, 30-01-2006 e 09-03-2006), e aqueles relativos às feminelas, em uma data (19-01-2006).

Dez cachos por repetição foram analisados quanto à massa fresca, diâmetro e comprimento. A massa fresca e o diâmetro de bagas foram avaliados em 20 bagas, amostradas em cada repetição. A massa fresca de cachos e de bagas foi quantificada em uma balança analítica. Nos cachos, o diâmetro e o comprimento foram quantificados com o auxílio de uma régua graduada, enquanto, nas bagas, o diâmetro foi quantificado com um paquímetro. As bagas foram analisadas a cada 15 dias, no mês de janeiro, e, a partir do mês de fevereiro, a cada sete dias, até a data de colheita, enquanto os cachos foram avaliados somente na data da colheita (24-03-2006).

A produção por planta $\left(\mathrm{g} \mathrm{planta}^{-1}\right)$ foi calculada levandose em conta a massa fresca dos cachos e o número de cachos por planta. A produtividade $\left(\mathrm{kg} \mathrm{ha}^{-1}\right)$ foi obtida a partir da densidade de plantas por hectare e da produção por planta. Além disso, utilizou-se dos dados de produção por planta em conjunto com a área foliar total, para determinar a área foliar por massa de fruto em cada planta, nas diferentes condições de cultivo.

O índice de Ravaz (g de frutos/g de ramos) foi quantificado segundo metodologia descrita por "Cus" (2004), reunindo-se e pesando-se todos os ramos eliminados em cada planta na poda da safra seguinte (21-08-2006), e relacionando-se esse peso com a produção de frutos determinada na data de colheita (24-032006).

A radiação fotossinteticamente ativa (RFA), acima do dossel e na altura dos cachos, foi determinada com um radiômetro portátil Li-Cor, modelo LI-185B. A relação vermelho (655-665nm) : vermelho distante $(725-735 \mathrm{~nm})(\mathrm{V}: \mathrm{Vd})$ foi determinada com um espectrorradiômetro portátil Li-Cor, modelo LI-1800. As 
quantificações de RFA e V:Vd foram obtidas em um dia de céu completamente limpo (09-03-2006), às 13h.

Os dados foram submetidos à análise de variância,e as médias, comparadas pelo teste de Tukey $(\mathrm{p}<0,05)$.

\section{RESULTADOS E DISCUSSÃO}

A cobertura reduziu em aproximadamente $30 \%$ a radiação fotossinteticamente ativa (RFA) incidente sobre o dossel das plantas (Tabela 1), semelhantemente ao observado por Rana et al. (2004) e, possivelmente, esteja relacionada às características físicas e químicas dos materiais de cobertura. Além disso, essas coberturas plásticas impermeáveis podem elevar a temperatura média no dossel vegetativo (Ferreira et al., 2004b; Papadakis et al., 2000), devido, principalmente, à restrição na velocidade de trocas de camadas de ar aquecido sobre as plantas. As coberturas também atuam como uma barreira física para a água das chuvas, fazendo com que a reposição hídrica fique condicionada ao suprimento de água da chuva que cai no espaço entre as filas de plantas.

Nestes contrastes de microclima, não houve diferença entre os tratamentos para a evolução dos estádios fenológicos (dados não-apresentados). Ferreira et al. (2004a) também não observaram diferenças fenológicas em videiras quando compararam as plantas cultivadas com e sem cobertura plástica. As plantas cobertas não apresentaram diferença quanto ao número total de ramos e gemas por planta, em comparação às plantas descobertas (Tabela 1). Isto mostra que a cobertura não restringiu a superação de dormência de gemas, na ausência de utilização de tratamento químico para este fim. Entretanto, em relação ao número de gemas mantido no momento da poda (Tabela 1), o número de ramos brotados em ambos os tratamentos foi muito baixo, em média de $61,3 \%$. Essa proporção de brotação salienta que, nesta safra, havia a necessidade de aplicação de cianamida hidrogenada, porém isso foi omitido para salientar possíveis efeitos que a cobertura possa proporcionar sobre esse componente de produção.

Os ramos das plantas cobertas apresentaram-se com maiores valores de massa fresca (Figura 1A) e crescimento longitudinal de entrenós (Figura 1B) em relação às plantas descobertas. Comportamento similar foi observado por Zanella et al. (2006), em mudas de maracujazeiro-amarelo submetidas a diferentes níveis de sombreamento. As videiras cobertas apresentam tendência ao estiolamento, com maior extensão dos entrenós, em resposta à redução da RFA e modificações na relação $\mathrm{V}: \mathrm{Vd}$. Os valores da relação $\mathrm{V}: \mathrm{Vd}$ sobre o dossel vegetativo das plantas cobertas e descobertas foram de 1,24 e 1,35 , respectivamente. De acordo com a literatura, a redução na relação V:Vd, através da percepção pelo complexo fitocromo, promove o estiolamento de tecidos vegetativos (Lambers et al., 1998).

$\mathrm{Na}$ área coberta, houve uma redução de $32,8 \%$ no número total de folhas por planta, em relação à área descoberta (Tabela 1). Isso pode ser explicado pela redução da largura do dossel (Tabela 1), por meio de podas verdes (despontes), com o intuito de manter o dossel sob a cobertura. Como os ramos das plantas cobertas apresentaram maior crescimento (comprimento de entrenós) (Figura 1A-B), o número de folhas por unidade de comprimento do ramo foi menor. Portanto, com os despontes nas áreas cobertas, o número de folhas que permaneceu nas plantas foi menor em relação às plantas descobertas. Há de se destacar ainda que houve redução no número de feminelas (ramos laterais) nas plantas cobertas (dados não-apresentados), já que o sombreamento favorece a dominância apical (Lambers et al., 1998), reduzindo assim a brotação de gemas laterais.

A restrição hídrica é outro fator que pode contribuir para a redução do número de brotações laterais (feminelas) sob as coberturas (Gu et al., 2004). Há de se destacar, ainda, que as condições de estiagem ocorridas no ciclo 2005/2006 na região, a partir do mês de novembro de 2005 (Figura 2), podem ter reduzido o suprimento de água às plantas cobertas. Nessas condições de restrição hídrica, a planta tende a reduzir o crescimento vegetativo, reduzindo assim a superfície de perda de água por transpiração (Souza et al., 2005).

Apesar dessas limitações em número de folhas, as plantas das áreas cobertas apresentaram, em folhas de ramos, maior área (Figura 1C) e massa seca (Figura 1D), e maior massa seca de feminelas (Tabela 1) em comparação às plantas descobertas. A maior expansão da lâmina foliar é normalmente observada em resposta à restrição de radiação (Lambers et al., 1998), ocorrida nas plantas cobertas (Tabela 1). Nas plantas cobertas, tanto para a massa seca como para a área foliar em folhas de ramos, os valores foram 23,0 a 34,5\% superiores (dependendo da data de coleta), enquanto, para as feminelas, a massa seca foliar foi $19,5 \%$ maior, em comparação às plantas descobertas. Como resultado, a área foliar específica foi similar entre os tratamentos (dados não-apresentados).

O número total de cachos por planta não foi influenciado pelos tratamentos (Tabela 1). Portanto, as condições microclimáticas impostas pela cobertura no ciclo anterior (2004/ 2005) não comprometeram o potencial de diferenciação e, conseqüentemente, a fertilidade de gemas nas videiras. No entanto, Ferreira et al. (2004a) obtiveram maior número de cachos em plantas descobertas em comparação a plantas cobertas da cultivar Niágara (Vitis labrusca). Todavia, os autores não descrevem o nível de sombreamento ocasionado pela cobertura utilizada no trabalho.

De modo geral, não houve diferença entre os tratamentos para os atributos avaliados nos cachos (Tabela 2). Porém, Ferreira et al. (2004a) observaram maiores valores de diâmetro e comprimento longitudinal de cachos em plantas com cobertura plástica em comparação às plantas descobertas. Isto pode ser uma característica de resposta de Vitis labrusca e dependente do nível de sombreamento imposto pela cobertura utilizada pelos autores. Lulu et al. (2005) observaram menor peso de cacho em plantas descobertas do que em plantas cobertas, o que, segundo os autores, pode estar relacionado ao maior murchamento e perda de bagas, ocasionado por doenças fúngicas.

O peso de cachos está diretamente relacionado com o número de bagas por cacho e o peso individual de bagas. No momento da colheita, não houve diferença entre os tratamentos para estes atributos (Tabela 1; Figura 1F). As condições 
microclimáticas promovidas pelas coberturas não interferiram no número de bagas, que é definido na diferenciação floral do ciclo anterior. Entretanto, com valores de RFA quantificada na altura dos cachos de $45 \mu \mathrm{mol} \mathrm{m}{ }^{-2} \mathrm{~s}^{-1}$, Hummell \& Ferree (1997) observaram reduções significativas no número de bagas por cacho em comparação à RFA de $225 \mu \mathrm{mol} \mathrm{m} \mathrm{m}^{-2} \mathrm{~s}^{-1}$ em videiras 'Seyval Blanc' e 'De Chaunac'. A RFA obtida na altura dos cachos, nas áreas cobertas e descobertas, foram de 202 e $96 \mu \mathrm{mol} \mathrm{m}^{-2} \mathrm{~s}^{-1}$, respectivamente, portanto superiores aos valores encontrados por Hummell \& Ferree (1997). Todavia, deve-se considerar que esse tipo de reposta depende do genótipo.

Nas áreas cobertas, houve maior taxa de crescimento em diâmetro e massa fresca das bagas quando se observa a evolução dessas características ao longo do ciclo (Figuras 1E-F). Essa antecipação no crescimento das bagas, nas plantas cobertas, pode ser resultado da ativação metabólica promovida pela maior temperatura neste ambiente (Ferreira et al., 2004a). Entretanto, próximo à colheita, não se observaram diferenças significativas nas dimensões das bagas entre os tratamentos, ocorrendo apenas oscilações em diâmetro (Figura 1E), em decorrência das precipitações ocorridas no período.

$\mathrm{O}$ rendimento de frutos não diferiu entre os tratamentos (Tabela 2), correspondendo a valores médios de $2.367 \mathrm{~g} \mathrm{planta}^{-1}$ e $6.484 \mathrm{~kg} \mathrm{ha}^{-1}$. Ferreira et al. (2004b), trabalhando com a mesma cultivar, também não obtiveram diferenças significativas entre áreas cobertas e descobertas, com uma produtividade média semelhante $\left(7.000 \mathrm{~kg} \mathrm{ha}^{-1}\right)$. O índice de Ravaz não diferiu entre os tratamentos sem $(2,6)$ e com cobertura $(3,3)$ (Tabela 2$)$. O índice de Ravaz ideal varia entre 5 (cultivares vigorosas) e 10 (cultivares pouco vigorosas) (Smart \& Robinson, 1992). Para videiras 'Cabernet Sauvignon', o índice de Ravaz ideal seria entre 4 e 6 (Cus, 2004). O principal fator que contribuiu para esse resultado, foi a reduzida carga de cachos por planta, em decorrência da baixa proporção de brotos, pois, no momento da poda, foram mantidas, em média, 41,5 gemas/planta, e obtiveram-se apenas 22,4 cachos/planta (Tabela 1), o que é condizente com o número médio de brotos por planta $(26,3)$. Deste modo, esse comportamento está muito aquém do potencial de produção por gema dessa cultivar. Isto pode estar relacionado com a baixa disponibilidade hídrica da safra anterior e/ou às variações de temperaturas (elevadas) no período hibernal (2004/2005), criando condições climáticas muito distintas das normalmente verificadas na região (Mandelli, 2005). Entretanto, apesar desse comportamento, as condições microclimáticas impostas pelas coberturas não comprometeram o potencial de rendimento da videira (Tabela 2).

A relação entre área foliar e massa fresca de fruto não foi influenciada pela cobertura plástica (Tabela 2). Deste modo, apesar da restrição em número de folhas (Tabela 1), conforme salientado anteriormente, a compensação em expansão de área foliar (Figura 1D) foi suficiente para garantir a mesma superfície de síntese de fotoassimilados por unidade de fruto. Contudo, para se ter uma conclusão do equilíbrio entre fonte e dreno, nas condições sob coberturas, serão necessários estudos visando avaliar a existência de incremento do potencial fotossintético por unidade foliar com redução de $30 \%$ na RFA. Folhas de sombra tendem a ter maior investimento no potencial fotossintético por unidade de área, além das modificações de área, devido ao maior investimento em número de cloroplastos e mudanças estruturais dessas organelas, que resultam em maior aproveitamento da radiação (Lambers et al., 1998).

Os resultados obtidos mostram que as restrições de radiação e de suprimento de água, ocasionados pela cobertura plástica translúcida e impermeável, não comprometeram o potencial de rendimento da cultivar Cabernet Sauvignon. Todavia, como as coberturas estimularam o crescimento vegetativo, isto exige maior cuidado com a poda verde.

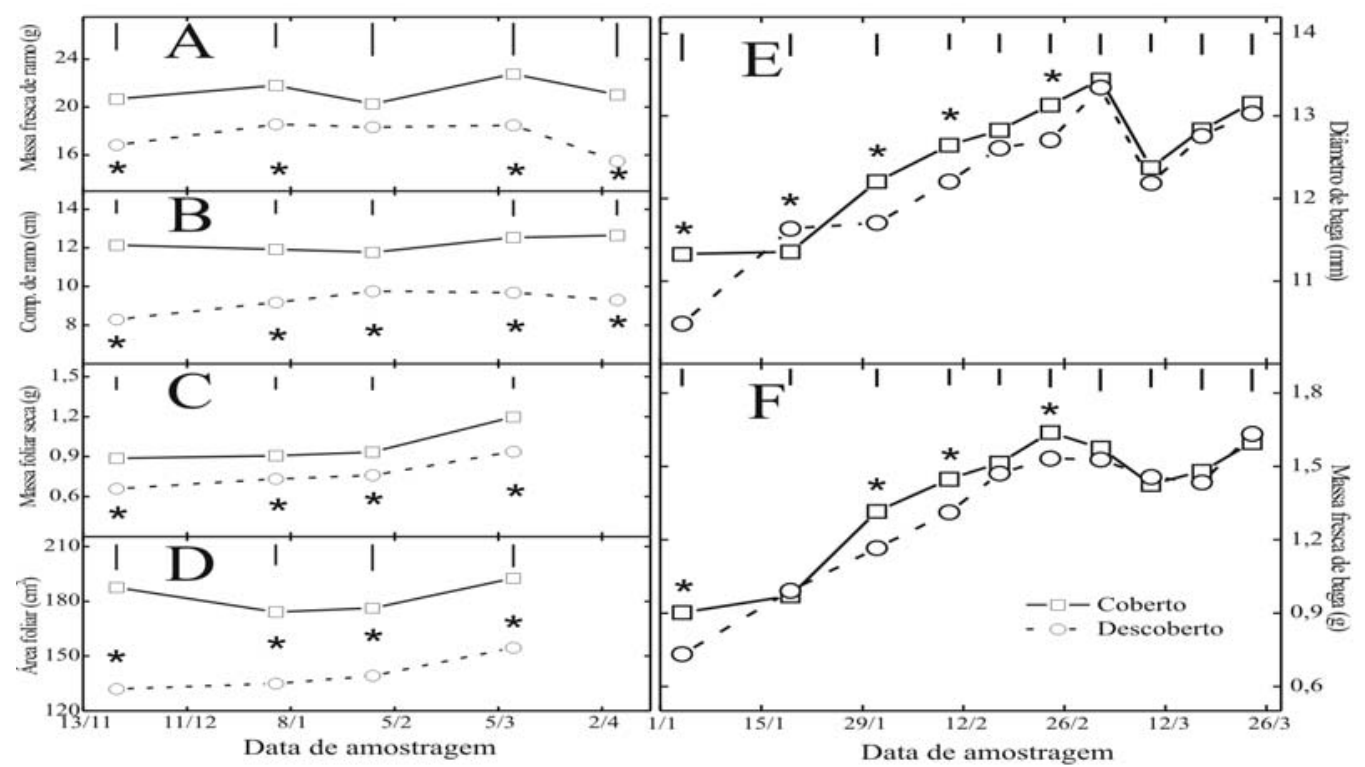

FIGURA 1 - Massa fresca (A) e comprimento médio de entrenós (B) de ramo, massa seca (C) e área (D) das folhas, e diâmetro (E) e massa fresca de bagas (F), em videiras 'Cabernet Sauvignon', provenientes de ambientes descoberto e coberto. Diferença mínima significativa entre tratamentos, calculadas através do teste de Tukey $(\mathrm{p}<0,05)$, para cada data de coleta, indicadas no interior da figura. O símbolo “*” indica diferença significativa entre tratamentos. 


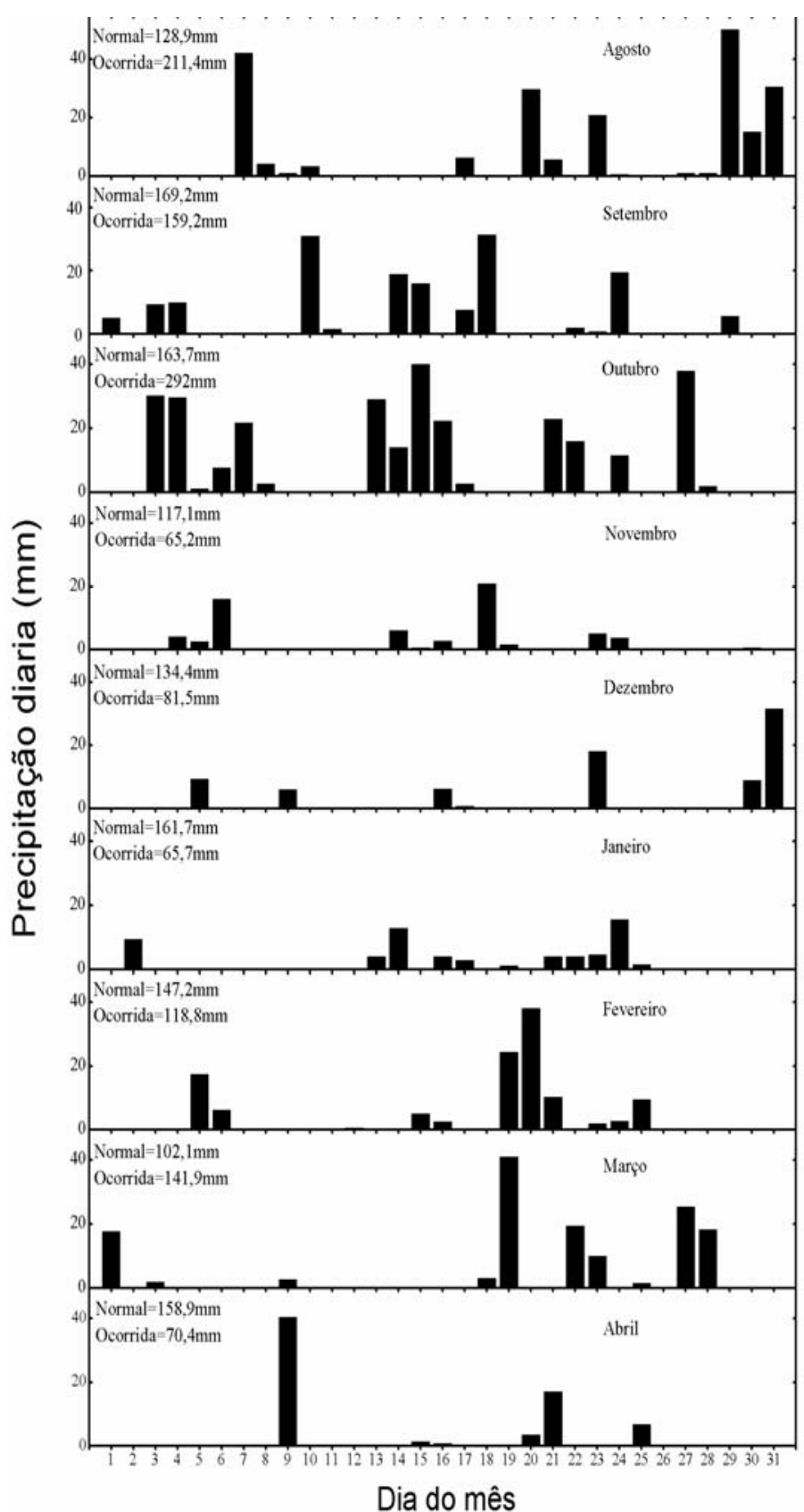

FIGURA 2 - Precipitações diárias e mensais (normais e ocorridas; indicadas no interior das figuras) registradas entre agosto de 2005 e abril de 2006, no Centro de Pesquisa em Agroindústria, localizado no município de Caxias do Sul-RS, com latitude $29^{\circ} 07^{\prime} 19^{\prime \prime}$, longitude $50^{\circ} 59^{\prime} 03^{\prime \prime} \mathrm{W}$ e altitude de $760 \mathrm{~m}$.

\section{CONCLUSÃO}

A cobertura plástica não interferiu na fenologia, na qualidade das gemas vegetativas e reprodutivas, nas dimensões e massa fresca de cachos e bagas, bem como no rendimento de frutos. Todavia, o uso de cobertura plástica promoveu maior crescimento vegetativo nos ramos principais.
TABELA 1 - Radiação fotossinteticamente ativa (RFA), número total de gemas, ramos, folhas e cachos por planta, número total de bagas por cacho, largura do dossel vegetativo, área foliar específica (AFEf) e massa foliar seca (MFSf) em folhas de feminelas, em videiras 'Cabernet Sauvignon', provenientes de ambientes descoberto e coberto.

\begin{tabular}{|c|c|c|c|c|c|c|c|c|c|}
\hline \multirow[t]{2}{*}{ Tratamento } & \multirow{2}{*}{$\begin{array}{l}\text { RFA } \\
(\%)\end{array}$} & \multicolumn{4}{|c|}{ Número por planta } & \multirow{2}{*}{$\begin{array}{l}\text { Bagas } \\
\text { por } \\
\text { cacho }\end{array}$} & \multirow{2}{*}{$\begin{array}{l}\text { Largura } \\
\text { dossel } \\
\text { (m) }\end{array}$} & \multirow{2}{*}{$\begin{array}{l}\text { AFf } \\
\left(\mathrm{cm}^{2}\right)\end{array}$} & \multirow{2}{*}{$\begin{array}{r}\text { MFSf } \\
(\mathrm{g})\end{array}$} \\
\hline & & $\overline{\text { Gemas }}$ & Ramos & Folhas & Cachos & & & & \\
\hline Descoberto & 100a & $40,6 \mathrm{a}$ & $27,4 a$ & $518,4 a$ & $23,5 \mathrm{a}$ & $75,3 \mathrm{a}$ & $1,75 a$ & $50,6 \mathrm{a}$ & 0,2056 \\
\hline Coberto & $71 \mathrm{~b}$ & $42,4 a$ & $25,3 \mathrm{a}$ & $348,4 b$ & $21,3 \mathrm{a}$ & $77,6 \mathrm{a}$ & $1,51 \mathrm{~b}$ & $57,3 \mathrm{a}$ & $0,246 \mathrm{a}$ \\
\hline$\overline{\text { C.V. }(\%)}$ & 18,6 & 17,2 & 19,0 & 30,9 & 35,2 & 15,2 & 9,4 & 18,0 & 23,6 \\
\hline
\end{tabular}

Valores seguidos da mesma letra, nas colunas, não diferem entre si, pelo teste de Tukey $(\mathrm{p}<0,05)$. (*) número de gemas que foram mantidas por planta no momento da poda (31-08-2005).

TABELA 2 - Diâmetro, comprimento e massa fresca (MF) dos cachos, rendimento ( $\mathrm{g}$ planta $^{-1} \mathrm{e} \mathrm{kg} \mathrm{ha}{ }^{-1}$ ), relação entre área foliar total e massa de frutos (AFT/MF) e índice de Ravaz, em videiras 'Cabernet Sauvignon', provenientes de ambientes descoberto e coberto. Dados obtidos no momento da colheita (24-03-2006).

\begin{tabular}{|c|c|c|c|c|c|c|c|}
\hline \multirow[t]{2}{*}{ Tratamento } & \multicolumn{3}{|c|}{ Cachos } & \multicolumn{2}{|c|}{ Rendimento } & \multirow{2}{*}{$\begin{array}{l}\text { AFT/MF } \\
\left(\mathrm{m}^{2} \mathrm{~kg}^{-1}\right)\end{array}$} & \multirow{2}{*}{$\begin{array}{c}\text { Índice } \\
\text { de } \\
\text { Ravaz }\end{array}$} \\
\hline & Diâm. (cm) & Comp. (cm) & $M F(g)$ & (g planta $\left.{ }^{-1}\right)$ & $\left(\mathrm{kg} \mathrm{ha}^{-1}\right)$ & & \\
\hline berto & 7,4a & $13,4 a$ & 104,1a & $2516 \mathrm{a}$ & $6892 a$ & $3,33 a$ & $2,58 \mathrm{a}$ \\
\hline Coberto & $7,9 \mathrm{a}$ & $13,9 \mathrm{a}$ & $107,3 \mathrm{a}$ & $2218 \mathrm{a}$ & $6075 \mathrm{a}$ & $3,15 \mathrm{a}$ & $3,34 a$ \\
\hline C.V. (\%) & 7,98 & 7,3 & 13,8 & 27.4 & 27.4 & 288 & 36.1 \\
\hline
\end{tabular}

Valores seguidos da mesma letra, nas colunas, não diferem entre si, pelo teste de Tukey $(\mathrm{p}<0,05)$

\section{AGRADECIMENTOS}

Os autores agradecem à CAPES e ao CNPq, pela concessão de Bolsas.

\section{REFERÊNCIAS}

CUS, F. The effect of different scion/rootstock combinations on yield properties of cv. 'Cabernet Sauvignon'. Acta Agriculturae Slovenica, Slovenia, v.83, n.1, p.63-71, 2004.

FARIAS, J.R.B.; BERGAMASCHI, H.; MARTINS, S.R.; BERLATO, M.A. Efeito da cobertura plástica de estufa sobre a radiação solar. Revista Brasileira Agrometeorologia, Santa Maria, v.1, n.1, p.31-36, 1993.

FERREIRA, E.A.; REGINA, M.A.; CHAFUN, N.N.J.;ANTINES, L.E.C. Antecipação de safra para videira 'Niágara Rosada' na região sul do estado de Minas Gerais. Ciência Agrotécnica, Lavras, v.28, n.6, p.1221-1227, 2004a.

FERREIRA, M.A.; PEDRO JUNIOR, M.J.; SANTOS, A.O.; HERNANDES, J.L. Modificação parcial do ambiente de cultivo da videira 'Cabernet Sauvignon' sobre diferentes porta-enxertos: efeito sobre a produção e o teor de sólidos solúveis. Bragantina, Campinas, v.63, n.3, p.439-445, 2004b. 
GU, S.; DU, G.; ZOLDOSKE, D.; HAKIM, A.; COCHRAN, R.; FUGELSANG, K.; JORGENSEN, G. Effects of irrigation amount on water relations, vegetative growth, yield and fruit composition of Sauvignon Blanc grapevines under partial rootzone drying and conventional irrigation in the San Joaquin Valley of California, USA. Journal of Horticultural Science and Biotechnology, Coventry, v.79, n.1, p.26-33, 2004.

HUMMELL, A.K.; FERREE, D.C. Response of two French hybrid wine-grape cultivars to low light environments. Fruit Varieties Journal, Urbana, v.51, n.2, p.101-111, 1997.

JACKSON, D.I.; LOMBARD, P.B. Environmental and management practices affecting grape composition and wine quality - a review. American Journal of Enology and Viticulture, Davis, v.44, n.4, p.409-430, 1993.

LAMBERS, H.; CHAPIN, F.S.; PONS, T.L. Plant physiological ecology. New York: Springer-Verlag, 1998. 540p.

LORENZ, D.H.; EICHHORN, K.W.; BLEIHOLDER, H.; KLOSE, R.; MEIER, U.; WEBER, E. Phenological growth stages of the grapevine (Vitis vinifera L. ssp. Vinifera) - Codes and descriptions according to the extended BBCH scale. Australian Journal of Grape and Wine Research, Adelaide, v.1, n.2, p.100-103, 1995.

LULU, J.; CASTRO, J.V.; PEDRO JUNIOR, M.J. Efeito do microclima na qualidade da uva de mesa 'Romana' (A 110) cultivada sob cobertura plástica. Revista Brasileira de Fruticultura, Jaboticabal, v. 27, n.3, p.422-425, 2005.

MANDELLI, F. Comportamento meteorológico e sua influência na vindima de 2005 na Serra Gaúcha. Bento Gonçalves: Embrapa Uva e Vinho, 2005. 4p. (Comunicado Técnico, 58).

MOTA, C.S. Ecofisiologia de videiras 'Cabernet Sauvignon' em sistema de cultivo protegido. 2007. 45f. Dissertação (Mestrado em Produção Vegetal) - Universidade do Estado de Santa Catarina, Lages, 2007.
PAPADAKIS, G.; BRIASSOULIS, D.; MUGNOZZA, G.S.; VOX, G.; FEUILLOLEY, P.; STOFFERS, J. A. Radiometric and thermal properties of, and testing methods for greenhouse covering materials. Journal of Agricultural Engineering Research, Karaj, v.77, n.1, p.7-38, 2000.

RANA, G.; KATERJI, N.; INTRONA, M.; HAMMAMI, A. Microclimate and plant water relationship of the "overhead" table grape vineyard managed with three different covering techniques. Scientia Horticulturae, Amsterdam, v. 102, p.105-120, 2004.

SMART, R.E.; COOMBE, B.G. Water relation of grapevines. In: Kozlowski, T.T. (Ed.). Water deficits and plant growth. Vol. VII. New York: Academic Press, 1983. p. 137-196.

SMART, R.; ROBINSON, M. Sunlight into wine: handbook for winegrape canopy management. Adelaide: Winetitles, 1991. 88p.

SOUZA, C.R.; MAROCO, J.P.; SANTOS, T.P.; RODRIGUES, M.L.; LOPES, C.; PEREIRA, J.S.; CHAVES, M.M. Control of stomatal aperture and carbon uptake by deficit irrigation in two grapevine cultivars. Agriculture, Ecosystems and Environment, Charlottetown, v.106, p.261-274, 2005.

TONIETTO, J. Clima. In: KUHN, G.B. (Ed.). Uva para processamento: produção, aspectos técnicos. Bento Gonçalves: Embrapa Uva e Vinho; Brasília: Embrapa informação tecnológica, 2003.p.27-33.

ZANELLA, F.; SONCELA, R.; LIMA, A.L.S. Formação de mudas de maracujazeiro "Amarelo" sob níveis de sombreamento em JiParaná-RO. Ciência e Agrotecnologia, Lavras, v. 30, n.5, p.880$884,2006$. 